\title{
Characteristics of Graves' Disease in Haemodialysis Patients
}

\author{
Karima Boubaker ${ }^{\mathrm{a}}$, Hayet Kaaroud ${ }^{\mathrm{a}}$, Hedi Ben Maiz ${ }^{\mathrm{a}, \mathrm{b}}$, Adel Kheder ${ }^{\mathrm{a}}$
}

\begin{abstract}
Abnormal thyroid hormone production and metabolism are relatively common in chronic renal failure and in regular haemodialysis. Chronic kidney disease is associated with decreased thyroid hormone concentrations, especially triiodothyronine (T3), which are referred to as the euthyroid sick syndrome associated with increased severity of non-thyroidal illness and mortality in cats and dogs. Hyperthyroidism is a very unusual condition in patients undergoing regular haemodialysis. Graves' disease is rare in these patients. To our knowledge, till now only 8 well documented cases of Graves' disease have been reported in patients undergoing regular haemodialysis. The diagonsis of Graves' disease must be evoked in presence or even in the absence of specific symptoms of the disease in haemodialysis patients. Diagnosis of hyperthyroidism may be difficult because of similar signs and symptoms as in uremia and manifestions are inhabitual. Indeed, hypertension, gynaecomastia, anaemia and hypercalemia can be seen in the two pathologies. Amost all patients undergoing regular haemodialysis received iodine 131 therapy for the treatment of Graves' disease. This treatment is efficient and safe. Isolation of the patient is not recommanded. The risk for dialysis staff is to be contaminated by an accidental ingestion of a biologic fluid from the patient. The usual protection barriers used during the haemodialysis session are sufficient.
\end{abstract}

Keywords: Hyperthyroidism; Graves's disease; Renal failure; Hemodialysis; 131 iodine; Radiation protection

\section{Introduction}

Abnormal thyroid hormone production and metabolism are relatively common in chronic renal failure and in regular haemodialysis. These disorders rarely lead to hyperthyroidism.

\footnotetext{
Manuscript accepted for publication November 29, 2012

anternal Medecine A Department, Charles Nicole Hospital,Tunisie

${ }^{b}$ Corresponding author: Hedi Ben Maiz, Laboratory of Research in

kidney Pathologies LR00SP01, Charles Nicole Hospital, Boulevard 9

Avril, 1006 Bab Souika, Tunisie. Email: ranou04@yahoo.fr
}

doi: http://dx.doi.org/10.4021/jem138e
Niemczyk reported 18 cases of hyperthyroidism among patients undergoing regular haemodialysis [1]. In a more recent review, the incidence of hyperthyroidism is $1.14 \%$ in haemodialysis patients, similar to the incidence in healthy individuals (1.1\%) [2]. Graves' disease is the prevalent aetiology of hyperthyroidism. It is a very unusual condition and is difficult to identify in patients undergoing regular haemodialysis.

\section{The Effect of Chronic Kidney Disease on Thy- roid Function}

Chronic kidney disease is associated with decreased thyroid hormone concentrations, which are referred to as the euthyroid sick syndrome. The decrease in thyroid hormones especially triiodothyronine (T3) is caused by changes in peripheral hormone metabolism due to a deceased extra thyroidal conversion of T4 to T3 and uptake of T4 and T3, impaired activity of nuclear receptors to $\mathrm{T} 3$ and post-receptor actions of T3, decease thyroid hormone binding proteins production and affinity for thyroid hormones and decrease in TSH secretion [3]. The hypothalamic- pituitary axis is intact in patients with chronic kidney disease. Euthyroid sick syndrome is associated with increased severity of non-thyroidal illness and mortality in cats and dogs [4-6]. Differentiation between hypothyroidism and euthyroid kidney disease can be performed by evaluation of thyroidal ${ }^{99 \mathrm{~m}} \mathrm{TcO}$ uptake [7] or TSH stimulation [8].

\section{Haemodialysis and Graves' Disease}

Although, the abnormal thyroid hormone production and metabolism are relatively common [9], hyperthyroidism is a very unusual condition in patients undergoing regular haemodialysis. Its incidence is $1.14 \%$, similar to the incidence in healthy individuals [2].

Graves' disease is the most common cause of hyperthyroidism. It is rare in patients undergoing regular haemodialysis. It is between five and ten times as common in females as in males. Diagnosis is usually made on the basis of symptoms, although thyroid hormone tests may be useful. Graves' 
disease can be occasionally associated with membraneous nephropathy and in some cases, the thyroid disorder has even been suspected of inducing the renal lesion mediated immune mechanism [10-13]. Classic Graves' disease associated with thyroid- stimulating hormone receptor antibodies developed in some patients undergoing regular hemodialysis $[14,15]$. To our knowledge till now only 8 well documented cases of Graves' disease have been reported in patients undergoing regular haemodialysis.

\section{Clinical Characteristics of Graves's Disease in Haemodialysis Patients}

The diagonsis of Graves' disease must be evoked in presence or even in the absence of specific symptoms of the disease in haemodialysis patients. The specific symptoms of Graves' disease are vascular goitre, exophthalmos and pretibial myxedema. Occasionally, goitre is not clinically detectable but may be seen only with X-ray computed tomography or ultrasound examination of the thyroid [16]. Highly suggestive symptoms of hyperthyroidism are irritability, weight loss, excessive sweating and hypertension [16]. Diagnosis of hyperthyroidism may be difficult because of similar signs and symptoms as in uremia and manifestions are inhabitual. Indeed, hypertension and gynaecomastia can be seen in two pathologies.

Thyroid hormones induce positive chronotrop effect with tachycardia $[17,18]$, positive inotrop effect $[19,20]$, increasement in the production of the vasoactives substances [21] and in renin-angiotensin-aldosteron system activity secondary to reduction in vascular reactivity, as well as increased B-adrenergic activity [22-25]. T3 stimulates directly renin-angiotensin-aldosteron system by a direct effect on the expression of renine gene [26].

Gynaecomastia is not unusual in Graves' disease because of the stimulatory effect of thyroid hormones on sex hormone binding globulin production leading to an increase in total oestradiol and testosterone, as well as a decrease in testosterone bioavailability associated with a compensatory rise in LH levels $[10,27]$. Gynaecomastia can also occur in chronic renal failure because of a decrease in the PTH hormone's clearance by the kidney or an increase in its production by the central nervous system $[10,28]$.

Cardiac manifestions reported are Wolff-ParkinsonWhite syndrome, paroxysatrial fibrillation [9] and angina pectoris, which may both have been manifestations of Graves' disease due to the increased oxygen demands [14].

\section{Biological Characteristics of Graves's Disease in Haemodialysis Patients}

Hyperthyroidism in Graves' disease is confirmed by elevat- ed blood levels of thyroid hormones (free T3 and T4) and a suppressed TSH. Thus, when hyperthyroidism is confirmed, or when blood results are inconclusive, thyroid antibodies should be measured for the diagnosis of Graves' disease. Graves' thyrotoxicosis can be quite severe with FT4 serum levels 3 to 4 times above normal [29]. Diagnosis of hyperthyroidism may be difficult because of similar signs and symptoms as in uremia and manifestions are inhabitual. Indeed, anaemia and hypercalemia can be seen in two pathologies. Anaemia is fequent in chronic renal failure. Hyperthyroidism is an unusual aetiology of anaemia with erythropoietin resistance [16, 30].

Chronic renal failure is a predisposing factor for the development of hypercalcaemia explained by a decrease in renal calcium excretion and due to a decrease in glomerular filtration rate $[31,32]$ or increase in fractional tubular calcium reabsorption $\mathrm{Na} / \mathrm{Ca}$ exchange along the distal tubules T4-mediated [33]. Hypercalcemia is encountred also in hyperthyroidism secondary to increase in bone turnover rates with elevated calcium entrance rate from the bone to the extracellular fluid space [34-36]. Serum 1, 25-(OH) 2D3 serum levels is normal to highnormal [33].

\section{Characteristics of Treatment of Graves' Dis- ease in Haemodialysis Patients}

Treatment of Graves' disease is efficient and resolves cardiac symptoms of the disease [9, 14]. Treatment of Graves' disease in these patients is initially antithyroid agent propylthiouracil $[9,15]$ and then iodine-131 therapy [15, 37]. The risk of the antithyroid agent propylthiouracil treatment is neutropenia. Iodine 131 therapy is prescribed for almost all aptients undergoing regular haemodialysis, paticularly for patients having thyroid carcinoma. Few well documented cases have been reported of patients treated with radioactive iodine for Graves' disease. It is imprtant to know pharmacokinetics and pharmacodynamic of this treatment in patients undergoing regular haemodialysis to get the radiation safety implications.

The usual dose of iodine therapy for thyroid carcinoma is reduced in haemodialysis patients compared to patients with normal renal function and varies from 25 to $100 \mathrm{Ci}$ [3840]. However, the daily dose for haemodialysed patients can be the same with patients having normal renal function since almost all the doses of tratment are eliminated by dialysis through diffusion because of the weak proteic liaison of the radioiodine [41]. The peak value is around the second day post administration [37]. More than $70 \%$ of the radioactivity is eliminatd after the first haemodialysis session [38, 42]. The effective half-life is 6.5 days [37]. From the third day, the clearance of 131 iodine was observed to be fairly constant and equated to $2.7 \%$ per day or $5.4 \%$ per dialysis session [37]. The biological half-life is 15 days [37]. The average 
dose rate over the effective treatment duration is $8 \mathrm{mSv} /$ hour at 1 meter distance and $2.6 \mathrm{mSv} /$ hour at 2 meter distance from the patient [37]. There is no detectable contamination of the dialysis unit, disposables, and bed linen [37].

\section{Radiation Protection}

In order to keep below a level of dose constraint of $3 \mathrm{mSv}$ and $1 \mathrm{mSv}$, the total allowable time spent at $1 \mathrm{~m}$ would be 15 hours and 5 hours per day, repectively [37]. These time limits are easy to respect. Isolation is not recommanded because the patient radiation level is less than $20 \mathrm{mSv} / \mathrm{hour}$ at one meter [42].

There are no definite recommendations for the first session [42]. However, liquid and solid wastes contaminated by radioactivity must be collected [42]. Thus, it seems necessary to collect dialysate and solid wastes and to stock them in a room dedicated to radiation decay because initial discharge concentration rates into the waste water system are estimated at $200 \mathrm{MBq} \mathrm{m} / 3$ hours $[37,42]$.

The risk for dialysis staff is to be contaminated by an accidental ingestion of a biologic fluid from the patient [42]. The usual protection barriers used during the haemodialysis session are sufficient: mask, gloves, overgarments, cap [42]. There is no risk linked to external exposure to radiations. The maximal theoretical dose received by the staff during the session is $65 \mathrm{mSv}$, while annual maximal dose for public exposed to radiations is $1000 \mathrm{mSv}$ [42].

\section{Conclusion}

The diagnosis of Graves' disease must be evoked even in the absence of specific symptoms in haemodialysis patients. In front of clinical symptoms, the conventional treatment is efficient and inoffensive. Iodine 131 therapy is frequently used. Isolation of the patient is not recommanded. The risk for dialysis staff is to be contaminated by an accidental ingestion of a biologic fluid from the patient. The usual protection barriers used during the haemodialysis session are sufficient.

\section{Conflict of Interest}

None declared.

\section{References}

1. Niemczyk S, Matuszkiewicz-Rowinska J, Stopinski M, Grochowski J, Sitkowska-Kurzec Z, Przedlacki J, Chojnowski K, et al. [Management of hyperthyroid- ism with radioactive iodine in end-stage renal disease patients undergoing dialysis]. Pol Arch Med Wewn. 2004;112(2):931-936.

2. Kutlay S, Atli T, Koseogullari O, Nergizoglu G, Duman N, Gullu S. Thyroid disorders in hemodialysis patients in an iodine-deficient community. Artif Organs. 2005;29(4):329-332.

3. van Hoek I, Daminet S. Interactions between thyroid and kidney function in pathological conditions of these organ systems: a review. Gen Comp Endocrinol. 2009;160(3):205-215.

4. Wakeling J, Moore K, Elliott J, Syme H. Diagnosis of hyperthyroidism in cats with mild chronic kidney disease. J Small Anim Pract. 2008;49(6):287-294.

5. Kantrowitz LB, Peterson ME, Melian C, Nichols R. Serum total thyroxine, total triiodothyronine, free thyroxine, and thyrotropin concentrations in dogs with nonthyroidal disease. J Am Vet Med Assoc. 2001;219(6):765-769.

6. Schoeman JP, Herrtage ME. Serum thyrotropin, thyroxine and free thyroxine concentrations as predictors of mortality in critically ill puppies with parvovirus infection: a model for human paediatric critical illness? Microbes Infect. 2008;10(2):203-207. 7. Diaz Espineira MM, Mol JA, Peeters ME, Pollak YW, Iversen L, van Dijk JE, Rijnberk A, et al. Assessment of thyroid function in dogs with low plasma thyroxine concentration. $\mathrm{J}$ Vet Intern Med. 2007;21(1):25-32.

8. Daminet S, Fifle L, Paradis M, Duchateau L, Moreau M. Use of recombinant human thyroid-stimulating hormone for thyrotropin stimulation test in healthy, hypothyroid and euthyroid sick dogs. Can Vet J. 2007;48(12):12731279.

9. Maruyama S, Ikarashi T, Soda S, Toya M, Okamura K, Hirayama S, Suzuki K, et al. A rare case of Graves' disease during regular hemodialysis. Clin Exp Nephrol. 2004;8(1):71-74.

10. CooperDS. Hyperthyroidism. Lancet.2003;362(9382):459468.

11. Toda T, Kimoto S, Nishio Y, Ehara T, Sasaki S. Sarcoidosis with membranous nephropathy and granulomatous interstitial nephritis. Intern Med. 1999;38(11):882-886.

12. Becker BA, Fenves AZ, Breslau NA. Membranous glomerulonephritis associated with Graves' disease. Am J Kidney Dis. 1999;33(2):369-373.

13. Sato Y, Sasaki M, Kan R, Osaku A, Koyama S, Shibayama S, Sato M, et al. Thyroid antigen-mediated glomerulonephritis in Graves' disease. Clin Nephrol. 1989;31(1):49-52.

14. Miyasaka Y, Yoshimura M, Tabata S, Shozu A, Nishikawa M, Iwasaka T, Inada M. Successful treatment of a patient with Graves' disease on hemodialysis complicated by antithyroid drug-induced granulocytopenia and angina pectoris. Thyroid. 1997;7(4):621-624.

15. McKillop JH, Leung AC, Wilson R. Successful manage- 
ment of Graves' disease in a patient undergoing regular dialysis therapy. Arch Intern Med. 1985;145(2):337339.

16. Boubaker K, Ounissi M, Khiari K, Harzallah A, Abbes M, El Younsi F, Ben Abdellah T, et al. [A rare case of Graves' disease in a patient on regular haemodialysis]. Nephrol Ther. 2010;6(4):251-254.

17. Kaptein EM, Quion-Verde H, Massry SG. Hemodynamic effects of thyroid hormone. Contrib Nephrol. 1984;41:151-159.

18. Hammond HK, White FC, Buxton IL, Saltzstein P, Brunton LL, Longhurst JC. Increased myocardial betareceptors and adrenergic responses in hyperthyroid pigs. Am J Physiol. 1987;252(2 Pt 2):H283-290.

19. Walker JD, Crawford FA, Kato S, Spinale FG. The novel effects of 3,5,3'-triiodo-L-thyronine on myocyte contractile function and beta-adrenergic responsiveness in dilated cardiomyopathy. J Thorac Cardiovasc Surg. 1994;108(4):672-679.

20. Kienle RD, Bruyette D, Pion PD. Effects of thyroid hormone and thyroid dysfunction on the cardiovascular system. Vet Clin North Am Small Anim Pract. 1994;24(3):495-507.

21. Quesada A, Sainz J, Wangensteen R, Rodriguez-Gomez I, Vargas F, Osuna A. Nitric oxide synthase activity in hyperthyroid and hypothyroid rats. Eur J Endocrinol. 2002;147(1):117-122.

22. Zwaveling J, Pfaffendorf M, van Zwieten PA. The direct effects of thyroid hormones on rat mesenteric resistance arteries. Fundam Clin Pharmacol. 1997;11(1):41-46.

23. Scivoletto R, Fortes ZB, Garcia-Leme J. Thyroid hormones and vascular reactivity: role of the endothelial cell. Eur J Pharmacol. 1986;129(3):271-278.

24. Napoli R, Biondi B, Guardasole V, Matarazzo M, Pardo F, Angelini V, Fazio S, et al. Impact of hyperthyroidism and its correction on vascular reactivity in humans. Circulation. 2001;104(25):3076-3080.

25. Haro JM, Sabio JM, Vargas F. Renal beta-adrenoceptors in thyroxine-treated rats. J Endocrinol Invest. 1992;15(8):605-608.

26. Koukoulis G, Polymeris A, Tzavara I, Pappas D, Thalassinos N. Normalization of thyroid hormone levels in patients with either hyper- or hypothyroidism results in a profound change of atrial natriuretic peptide (ANP) levels. Hormones (Athens). 2002;1(2):104-112.

27. Abalovich M, Levalle O, Hermes R, Scaglia H, Aranda C, Zylbersztein C, Oneto A, et al. Hypothalamic-pituitary-testicular axis and seminal parameters in hyperthyroid males. Thyroid. 1999;9(9):857-863.

28. Leavey SF, Weitzel WF. Endocrine abnormalities in chronic renal failure. Endocrinol Metab Clin North Am. 2002;31(1):107-119.

29. Poulin S, Brossard JH, Noel R, Isenring P. Hypercal- caemia in a patient with membraneous nephropathy. Nephrol Dial Transplant. 2006;21(5):1434-1438.

30. Kaynar K, Ozkan G, Erem C, Gul S, Yilmaz M, Sonmez B, Ozdemir F, et al. An unusual etiology of erythropoietin resistance: hyperthyroidism. Ren Fail. 2007;29(6):759761.

31. Stanbury SW, Lumb GA. Metabolic studies of renal osteodystrophy. I. Calcium, phosphorus and nitrogen metabolism in rickets, osteomalacia and hyperparathyroidism complicating chronic uremia and in the osteomalacia of the adult Fanconi syndrome. Medicine (Baltimore). 1962;41:1-34.

32. Marone CC, Wong NL, Sutton RA, Dirks JH. Acidosis and renal calcium excretion in experimental chronic renal failure. Nephron. 1981;28(6):294-296.

33. Iqbal AA, Burgess EH, Gallina DL, Nanes MS, Cook CB. Hypercalcemia in hyperthyroidism: patterns of serum calcium, parathyroid hormone, and 1,25-dihydroxyvitamin D3 levels during management of thyrotoxicosis. Endocr Pract. 2003;9(6):517-521.

34. McCaffrey C, Quamme GA. Effects of thyroid status on renal calcium and magnesium handling. Can J Comp Med. 1984;48(1):51-57.

35. Kumar V, Prasad R. Molecular basis of renal handling of calcium in response to thyroid hormone status of rat. Biochim Biophys Acta. 2002;1586(3):331-343.

36. Peng JB, Brown EM, Hediger MA. Apical entry channels in calcium-transporting epithelia. News Physiol Sci. 2003; 18:158-163.

37. Simpson JB, Godwin GA. Radiation safety implications of 131I treatment in a patient with Grave's disease undergoing home hemodialysis. Health Phys. 2006;91(6):570-573.

38. Sinsakul M, Ali A. Radioactive 131I use in end-stage renal disease: nightmare or nuisance? Semin Dial. 2004;17(1):53-56.

39. Mello AM, Isaacs R, Petersen J, Kronenberger S, McDougall IR. Management of thyroid papillary carcinoma with radioiodine in a patient with end stage renal disease on hemodialysis. Clin Nucl Med. 1994;19(9):776-781.

40. Daumerie C, Vynckier S, Caussin J, Jadoul M, Squifflet JP, de Patoul N, Wambersie A. Radioiodine treatment of thyroid carcinoma in patients on maintenance hemodialysis. Thyroid. 1996;6(4):301-304.

41. Magne N, Magne J, Bracco J, Bussiere F. Disposition of radioiodine (131)I therapy for thyroid carcinoma in a patient with severely impaired renal function on chronic dialysis: a case report. Jpn J Clin Oncol. 2002;32(6):202205.

42. Brunet P, Bourrelly M, Mundler O, Bouvier C, Faure V, Opris A, Bouchouareb D, et al. [Hemodialysis procedure in a patient treated with radioactive iodine]. Nephrol Ther. 2008;4(3):196-201. 